\section{ON A METHOD OF MEASURING CONTACT ELECTRICITY ${ }^{1}$}

IN my reprint of papers on electrostatics and magnetism ( $\$ 400$, of date January, 1862) I described briefly this method, in connection with a new physical principle, for exhibiting contact electricity by means of copper and zinc quadrants substituted for the uniform brass quadrants of my quadıant electrometer. I had used the same method, but with movable disks for the contact electricity, after the method of Volta, and my own quadrant electrometer substituted for the gold-leaf electroscope by which Volta himself obtained his electric indications, in an extensive series of experiments which 1 made in the years $1859-61$.

I was on the point of transmitting to the Royal Society a paper which I had written describing these experiments, and which I still have in manuscript, when I found a paper by Hankel in Poggendorff's Annalen for January, 1862, in which results altogether in accordance with my own were given, and I withheld my paper till I might be able not merely to describe a new method, but if possible add something to the valuable information regarding properties of matter to be found in Hankel's paper. I have made many experiments from time to time since $186 \mathrm{r}$ by the same method; but have obtained results merely confirmatory of what had been published by Pfaff in 1820 or 1821 , showing the phenomena of contact electricity to be independent of the sur. rounding gas, and agreeing in the main with the numerical values of the contact differences of different metals which Hankel had published; and I have therefore hitherto published nothing except the slight statements regarding contact electricity which appear in my "Electrostatics and Magnetism." As interest has been recently revived in the subject of contact electricity, the following description of my method may possibly prove useful to experimenters. The same method has been used to very good effect, but with a Bohnenberger electroscope instead of my quadrant electrometer, in researches on contact electricity by $\mathrm{Mr}$. H. Pellat, described in the Journal de Physique for May 1880.

The apparatus used in these experiments was designed to secure the following conditions:-To support two circular disks of metal about four inches in diameter in such a way that the opposing surfaces should be exactly parallel to each other and approximately horizontal, and that the distance between them might be varied at pleasure from a shortest distance of about one-fiftieth of an inch to about a quarter or half an inch. This part of the apparatus I have called a "Volta-condenser." The lower plate, which was the insulated one, was fixed on a glass

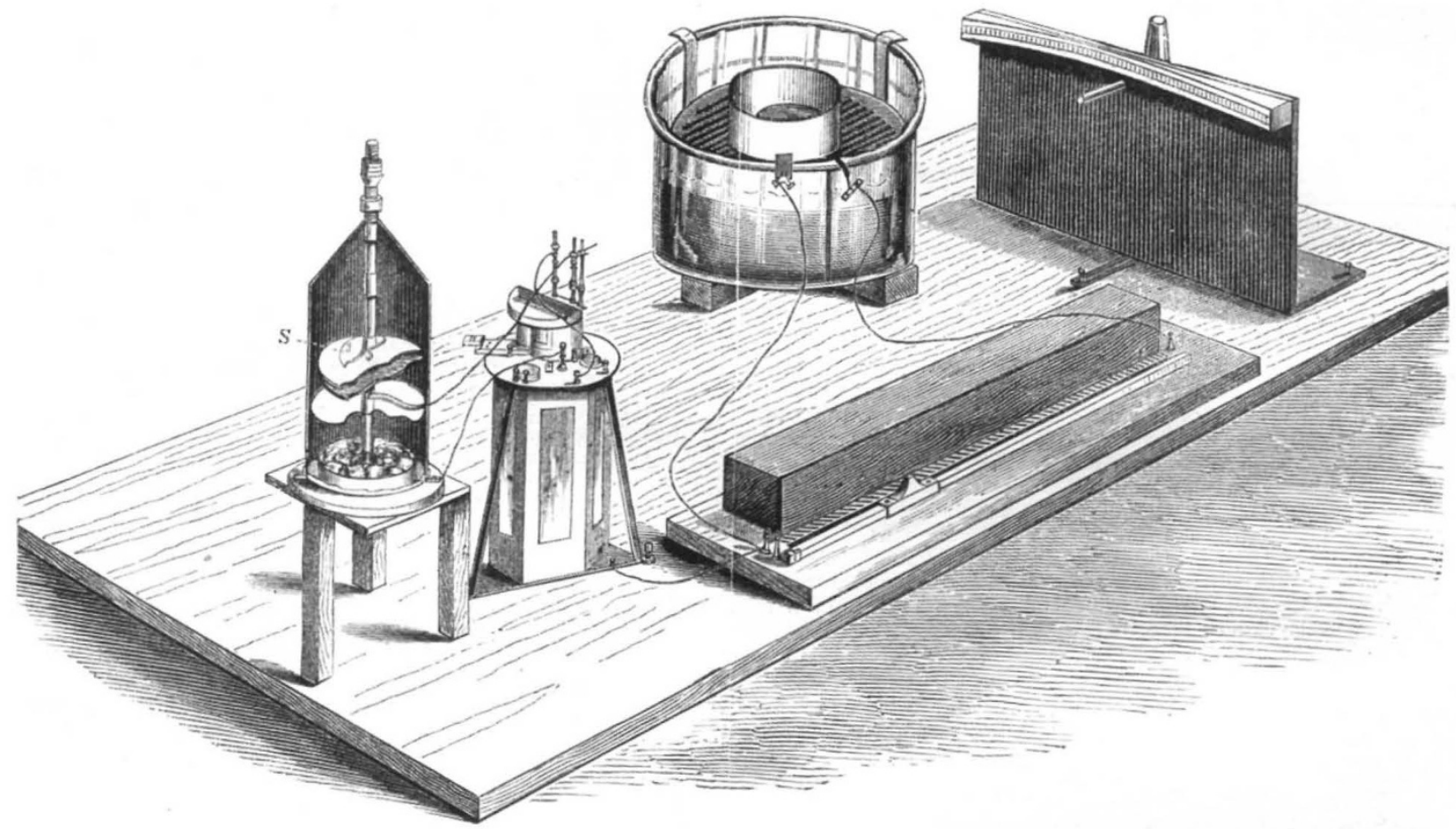

stem rising from the centre of a cast-iron sole plate. The upper plate was suspended by a chain to the lower end of a brass rod sliding through a steadying socket in the upper part of the case. A stout brass flange fixed to the lower end of this rod bears three screws, one of which, $S$, is shown in the drawing, by which the upper plate can be adjusted to parallelism to the lower plate. The other apparatus used consisted of a quadrant electrometer, and in my original experiments an ordinary Daniell's cell, in my later ones a gravity Daniell's cell of the form which I described in Proc. R.S. 1871 (pp. 253-259) with a divider by which any integral number of per cents. from o to 100 of the electromotive force of the cell could be established between any two mutually insulated homogeneous metals in the apparatus.

Connections. - The insulated plate was connected by a brass wire passing through the case of the Volta-condenser to the electrode of the insulated pair of quadrants. The upper plate was connected to the metal case of the Volta-condenser and to the metal case of the electrometer, one pair of quadrants of which were also connected to the case. One of the terminals of the divider, which connected the poles of the cell, was connected

¿ By Prof. Sir William Thomson, M.A., F.R.S. ; being a paper read before Section A of the British Association at Swansea, x880, with additions. to the case of the electrometer, and to the other terminal was attached one of the contact wires, which was a length of insu. lated copper wire having soldered to its outer end a short piece of platinum. The other contact surface was a similar short piece of platinum fixed to the insulated electrode of the electrometer. Hence it will be seen that metallic connection between the two plates was effected by putting the divider at zero and bringing into contact the two pieces of platinum wire.

Order of Experiment. - The sliding piece of the divider was put to zero, and contact made and broken and the upper plate raised: then the deflection of the spot of light was observed. These operations were repeated with the sliding piece at different numbers on the divider scale until one was found at which the make-break and separation caused no perceptible deflection. The number thus found on the divider scale was the number of per cents. which was equal to the contact electric difference of the plates in the Volta-condenser.

[Addendum, November 23, 1880.-Since the communicatic of this paper to the British Association, I have found that a dry platinum disk, kept for some time in dry hydrogen gas, and then put into its position in dry atmospheric air in the Volta-condenser, becomes positive to another platinum disk 
which had not been so treated, but had simply been left undis. turbed in the apparatus. The positive quality thus produced by the hydrogen diminishes gradually, and becomes insensible after two or three days.]

P.S.-On December 24, 1880, one of two platinum plates in the Volta-condenser was taken out; placed in dried oxygen gas for forty-five minutes ; taken out, carried by hand, and replaced in the Volta-condenser at $\mathbf{1 2 . 3 0}$ on that day. It was then found to be negative to the platinum plate, which had been left undisturbed. The amount of the difference was about 33 of a volt. The plates were left undisturbed for seventeen minutes in the condenser; and were then tested again, and the difference was found to have fallen to 29 of a volt. At noon on the 25th they were again tested, and the difference found to be -18. The differences had been tested from time to time since that day, the plates having been left in the condenser undisturbed in the intervals. The following Table shows the whole series of these results :-

Time.

Electric difference between surfaces of a platinum plate in natural condition, and a platinum plate after 45 minutes' exposure to dry oxygen gas.

Dec. 24, I2.30 p.m. 33 of a volt. 24, 12.47 p.m 25 , noon ... 27 , noon $\ldots$ 28 , I 1.20 a.m. $3 \mathrm{I}$, noon

Jan. 4, II.0 a.m. I I, I I.40 a.m. 29 , 18 , 116 097$$
047
$$$$
\text { ... } 042
$$$$
\mathrm{O} 20
$$

,

, ",

Mr. Rennie, by whom these experiments were made during the recent Christmas holidays, had previously experimented on a platinum plate which had been made the positive pole in an electrolytic cell with an electromotive force of one volt, tending to decompose water acidulated with sulphuric acid; the other pole being a piece of platinum wire. After the plate had been one hour under this influence in the electrolytic cell he removed it, and dried it by lightly rubbing it with a piece of linen cloth. He then placed it in the Volta-condenser, and found it to be negative to a platinum plate in ordinary condition; the difference observed was 27 of a volt. This experiment was made on October $2 \mathbf{I}$; and on November 8 it was found that the difference had fallen from $\cdot 27$ to 07 . Mr. Rennie also made similar experiments with the platinum disk made the negative pole in an electrolytic cell, and found that this rendered the platinum positive to undisturbed platinum to a degree equal to about $\mathrm{O}$ of a volt. The effect of soaking the platinum plate in dry hydrogen gas, alluded to in my first postscript, which also was observed by Mr. Rennie, was found to be about 'II of a volt. Thus in the case of polarisation by hydrogen, as well as in the case of polarisation by oxygen, the effect of exposure to the dry gas was considerably greater than the effect of electro-plating the platinum with the gas by the electromotive force of one volt.

\section{THE NAVAL ARCHITECTS}

\section{$\mathrm{T}$}

$\mathrm{E}$ session of the Institution of Naval Architects just con cluded was remarkable for the number of papers on the use of steel both for shipbuilding and marine engineering. This was perhaps to be expected in consequence of the commotion among steel-users caused by the total failure of the steel plates supplied for the boilers of the Russian yacht Livadia. Accordingly we find four papers on this subject. The first, by $\mathrm{Mr}$. Samuda, deals with the effect which the introduction of steel hulls and steel-faced armour has had upon the design of ships of war. This paper is based upon the results attained by the author with a steel corvette which he has recently constructed for the Argentine Government. The dimensions of this vessel as actually constructed, and the corresponding dimensions which must of necessity have been adopted, had the material of construction been iron instead of steel, should be carefully noted in order to appreciate the true benefits to be derived from the use of the latter material.

The vessel as actually constructed is 240 feet long by 50 feet wide ; the displacement is 4200 tons, the power 4500 horses, and the coal-supply 650 tons, which is sufficient to allow her to steam 6000 miles at a speed of $8 \mathrm{knots}$, or 4300 miles at a speed of 10 knots. The speed which it is expected will be attained on the measured mile is $13^{\frac{3}{4}}$ knots. If the vessel had been built of iron and cased with iron armour, the speed and shot-resisting power remaining the same, the dimensions would have been as follows :-Length, 260 feet; breadth, 55 feet; displacement, 5200 tons; power, 5000 horses ; and coal-supply, 720 tons. This example is a very good illustration of the great benefit which naval architects will derive from the use of steel, a benefit, be it remarked, which comes most opportunely in these days of powerful ordnance; for not only has the steel-faced armour about 25 per cent. more resisting power than an equal thickness of iron, but also the weight saved in the hull and machinery by the use of steel enables a greater quantity of armour to be carried.

The second paper on steel was by Mr. W. Parker, Chief Engineer Surveyor to Lloyd's Registry, "On the Causes of the Failure of the Steel Plates supplied for the Boilers of the Livadia." Steel, as is well known, had formerly a bad reputation for treachery and uncertainty of behaviour. Latterly however a more intimate knowledge of the methods of manufacture and a better acquaintance with the processes of working had apparently quite removed this impediment to its general introduction. The failure therefore above referred to came as a surprise to shipbuilders, and the circumstances demanded and received a most searching inquiry at the hands of the engineer officers of Lloyd's. It was found that samples cut from the broken plates fulfilled every test demanded by Lloyd's, the Admiralty, and the Board of Trade. The tensile strength proved to vary between the very narrow limits of $26 \cdot \mathrm{r}$ and $28 \cdot 3$ tons per square inch. The elongation after fracture of samples 8 inches in length ranged from $27^{\circ} 3$ to $34^{\circ} 3$ per cent. Nevertheless in spite of the apparently excellent quality of the plates, it was found that after they had been punched and worked into place they had become so brittle as to be unable to stand the hydraulic proofs to which it is usual to subject boilers, and in some instances even, the plates cracked before the hydraulic test was applied. The further investigations of $\mathrm{Mr}$. Parker proved that whenever samples of the plates were punched, the material became so brittle as to break into pieces under the blow of an ordinary sledge-hammer; the tensile strength dropped to 18.4 tons per square inch, and the extensibility disappeared altogether.

Specimens were next subjected to chemical analysis, with the result of proving that, the material was from the chemical point of view far from homogeneous. A portion of the plates, about 8 inches long by 4 inches wide, was carefully freed from rust by grinding, and successive layers were planed off from one side to the other. Each layer was one-sixteenth of an inch in thickness, and they were numbered in succession as they were planed off. The result of analysis showed that the quantities of carbon, manganese, sulphur, and phosphorus varied in an extraordinary digree. These differences in the chemical composition, however, did not satisfactorily account for the behaviour of the metal. It was not till the appearance of the fractures suggested, that the material had not been properly worked under the hammer and rolls, that a really satisfactory solution of the mystery was arrived at. "A piece cut from the fractured plate was raised to a red heat and rolled to half its original thickness. Strips were then cut from this $\frac{3}{8}$.inch plate, and punched with holes $\frac{1}{2}$ inch diameter, being one half the size of those in the $\frac{8}{4}$-inch plate. This extra work on the material seemed to raise its ductility appreciably, the strips being found to bend well after punching, several of them bending to right angles, and only one of them breaking short off, while none of them showed such extraordinary signs of brittleness as were observable in the material when of the original thickness. Three pieces tested for tensile strength after rolling broke under a stress of 33 tons, $34^{\prime 25}$ tons, and $32^{\prime} 3$ tons per square inch respectively, with an elongation in 8 inches of 12 per cent., II 25 per cent., and 17.5 per cent. respectively, the last-mentioned specimen being annealed."

Mr. Parker concludes his paper by expressing the hope that the facts which he was able to lay before the meeting will tend to allay alarm and to strengthen confidence in the use of mild steel for constructive purposes. When it is considered what an enormous quantity of this material is now being used in the construction of marine boilers, as well as for the hulls of vessels, this wish will be heartily re-echoed. In the spring of 1878 there were only two marine boilers of the modern form made of mild steel in existence. Within twelve months subsequently to that date 120 steamers had been fitted with boilers of this material, and during the same period in the following year 280 vessels more. At the present moment there are no less than $x$ IOO steel boilers in use in steamships, weighing together $n v^{a r}$ 7, 000 tons. 